(AOSD); all were exposed to a biologic agent: 16 Etanercept (ETA), 7 Adalimumab (ADA), 4 Infliximab (IFX), 1 Certolizumab (CTZ), 5 Rituximab (RTX), 1 Anakinra (ANK). Median age was 34 yrs (range 24-50). All patients treated with TNFi and ANK withdrew therapy in early pregnancy ( $<10$ weeks gestational age). 2 RA patients had 2 pregnancies each, during ETA treatment. A RA woman became pregnant 4 times during RTX therapy. 10 patients were also on csDMARDs therapy at the time of conceptions: 7 Hydroxycloroquine (HCQ), $1 \mathrm{HCQ}+$ Sulphasalazine (SSZ), 1 Cyclosporine A (CYA), which was continued, and 1 with Methotrexate which was immediately withdrawn. 1 RA patient started SSZ from the 24th week. 15 patients (7 RA, 2 PsA, 2 AS, 2 uSpA, 1 DM) started or increased oral and/or intra-articular steroids because of disease flare. A control group of 45 pregnancies observed in 42 patients not exposed to biologics was selected="selected" (19 RA, 12 uSpA, 3 Juvenile Idiopatic Arthritis (JIA), 5 PsA, 1 AS, 1 DM, 1 AOSD), median age 35 (range 22-42). 18 patients were treated with csDMARDs during pregnancy (8 HCQ; 4 SSZ; 2 CYA+HCQ; $4 \mathrm{SSZ}+\mathrm{HCQ}$ ). No other drugs were taken at the time of conception, apart from low dose of steroids in 24 cases; in 1 case intra-articular steroids were given because of disease flare.

Pregnancy outcomes are summarized in tab.1: therapeutic abortions were performed for an extrauterine pregnancy occurred twice in the patient with RA who became pregnant 4 times during RTX treatment, after the 5th and the 6th retreatment. After the 4 th retreatment she had an early spontaneous abortion. Previously, she delivered 2 healthy children after exposure to ETA and 3 treatment cycles of RTX. No serious perinatal complication occurred, excluding very preterm baby delivery at 28 th weeks, who needed neonatal intensive care. No congenital malformations were observed. Klinefelter syndrome was diagnosed in 1 case.

Tab. 1: Pregnancy outcomes of women with $\mathrm{RD}$ exposed to biological $(\mathrm{BE})$ compared with pregnant women with $\mathrm{RD}$

\begin{tabular}{|c|c|c|c|}
\hline & $\mathrm{BE}$ group (34) & NE group (45) & $p$ \\
\hline Live births & $29(85,3 \%)$ & $43(95,5 \%)$ & ns \\
\hline Spontaneous abortion & $2(5,9 \%)$ & $2(4,4 \%)$ & $\mathrm{ns}$ \\
\hline Therapentic abortion & $2(5,9 \%)$ & 0 & ns \\
\hline Voluntary interuption of pregnancy & $1(2.9 \%)$ & 0 & ns \\
\hline Pre-term delivery & $5(14,7 \%)$ & $6(13,3 \%)$ & ns \\
\hline Preterm nupture of membrane & $3(8,8 \%)$ & $4(8,9 \%)$ & $\mathrm{ns}$ \\
\hline Intra-uterine growth restriction & $1(2,9 \%)$ & $1(2,2 \%)$ & ns \\
\hline Average birth weight & $2875 \mathrm{~g}(720-4234)$ & $3140(1880-4200)$ & ns \\
\hline Low birth weight $(<2500 \mathrm{~g})$ & $6(17,6 \%)$ & $5(11.1 \%)$ & ns \\
\hline
\end{tabular}

Conclusions: In our case series no significant differences did occur in pregnancy outcome between BE and NE group, according to the most recent data published in literature. Additional data from larger numbers of pregnacy exposed to biological agents are required.

Disclosure of Interest: None declared

DOI: 10.1136/annrheumdis-2017-eular.4929

\section{SAT0157 MYCOBACTERIUM TUBERCULOSIS SPECIFIC RESPONSES FROM CD8+ AND CD4+ T CELLS IN PATIENTS WITH LATENT AND ACTIVE FORM OF TUBERCULOSIS}

E. Zanova ${ }^{1}$, D. Kozakova ${ }^{1}$, M. Polanova ${ }^{2}$, I. Solovic ${ }^{2}$, I. Rybar ${ }^{3} .{ }^{1}$ National Institute of Rheumatic Diseases, Pieštany; ${ }^{2}$ National Institute of Tuberculosis, Pulmonary Diseases and Thorax Surgery, Vysne Hagy; ${ }^{3}$ Slovak Health University, Bratislava, Slovakia

Background: Testing the presence of latent or active tuberculosis using IGRA tests is necessary part of the diagnostic screening at risk individuals. QuantiFERON-TB Gold Plus (QFT-Plus) is a test for cell-mediated immune (CMI) responses to peptide antigens that simulate mycobacterial proteins. Peptide antigens in TB1 tube elicit CMI responses from CD4+ T-helper lymphocytes, in TB2 tube from CD8+ T-cytotoxic lymphocytes. Test is based on the ability of effector T lymphocytes to produce the cytokine interferon gamma (IFN- $\gamma$ ).

Objectives: To compare and evaluate levels of IFN $-\gamma$ produced by $\mathrm{CD} 4+$ and CD8+ cells in TB1 and TB2 tubes.

Methods: It was studied 33 subjects with latent form of tuberculosis (LTBI) and 33 subjects with active TB. QFT-Plus was used to detect in vitro responses to peptide antigens associated with Mycobacterium tuberculosis infection (ELISA, QIAGEN). Results were obtained by calculation of INF- $\gamma$ levels in Mitogen, TB antigen (TB1, TB2) and Negative control tubes using QFT analysis software.

Results: QFT-Plus positive results were observed in both groups of people. Increased levels of IFN- $\gamma$ produced by $\mathrm{CD} 4+$ cells (TB1) has been detected in 21 subjects with LTBI $(63,64 \%)$ and in all 33 subjects with active TB $(100,0 \%)$. Increased levels of IFN- $\gamma$ produced by CD8+ cells (TB2) has been detected in 27 people with LTBI $(81,82 \%)$ and in all 33 people with active TB $(100,0 \%)$. Joint increase levels of IFN- $\gamma$ in the tubes TB1 and TB2 was observed in 16 individuals with LTBI $(48,48 \%)$ and in all 33 individuals with active TB (100,0\%). In the group of patients with a negative QFT-Plus it was not observed increased levels of IFN in tubes TB1 and TB2.

Conclusions: Our findings confirm specific CD4+ and CD8+ T cell response to mycobacterial protein antigens in individuals with LTBI and also in active TB subjects, in which INF- $\gamma$ was frequently found. The immunological response represented by $\mathrm{CD} 4+$ and $\mathrm{CD} 8+\mathrm{T}$ cells was not detected in subjects with QFT-Plus negative.

Disclosure of Interest: None declared
DOI: 10.1136/annrheumdis-2017-eular.5611

\section{SAT0158 EFFICACY OF SWITCHING FROM ETANERCEPT TO ADALIMUMAB IN RHEUMATOID ARTHRITIS AND PSORIATIC ARTHRITIS PATIENTS WHO EXPERIENCED A FIRST-LINE BIOLOGIC THERAPY FAILURE: THE FEARLESS STUDY}

E.G. Favalli ${ }^{1}$, A. Becciolini ${ }^{1}$, A. Carletto ${ }^{2}$, F. Conti ${ }^{3}$, G. Amato ${ }^{4}$, E. Fusaro ${ }^{5}$, L. Quartuccio ${ }^{6}$, A. Lo Monaco ${ }^{7}$, M. Benucci $^{8}$, F. Salaffi ${ }^{9}$, A. Semeraro ${ }^{10}$, M. Biggioggero ${ }^{11}$, S. Parisi ${ }^{5}$, F. Ceccarelli ${ }^{3}$, I. Piazza ${ }^{2}$, R. Foti ${ }^{4} .{ }^{1}$ Department of Rheumatology, Gaetano Pini Institute, Milano; ${ }^{2}$ Rheumatology Unit, AOUI, Verona; ${ }^{3}$ Dipartimento di Medicina Interna e Specialità Mediche, Reumatologia, Sapienza Università di Roma, Roma; ${ }^{4}$ Rheumatology Unit, A.O.U. Policlinico Vittorio Emanuele, Catania; ${ }^{5}$ Rheumatology, Azienda Ospedaliera Universitaria Città della Salute e della Scienza, Torino; ${ }^{6}$ Clinica di reumatologia, Dipartimento di scienze mediche e biologiche, ASUIUD, Udine; ${ }^{7}$ UOC di Reumatologia, Azienda Ospedaliero-Universitaria Sant'Anna Cona-Ferrara, Ferrara; ${ }^{8}$ SOS Reumatologia, Ospedale S. Giovanni di Dio, Firenze; ${ }^{9}$ Clinica Reumatologica, Università Politecnica delle Marche, Ancona; ${ }^{10}$ U. O. Reumatologia, ASL Taranto-PP.OO.SS. Annunziata Taranto e Valle d'Itria, Taranto; ${ }^{11}$ Department of Clinical Sciences and Community Health, Division of Rheumatology, University of Milan and Gaetano Pini Institute, Milano, Italy

Background: The strategy for the choice of the second biologic agent after the failure of the first TNF inhibitor (TNFi) is still an unclear aspect in the treatment of both rheumatoid arthritis (RA) and psoriatic arthritis (PsA). Switching between structurally different TNFis (from etanercept [ETN] to monoclonal antibody [mAb] or vice versa) has been proposed as a more effective procedure than switching among different mAbs, but to date no study has been specifically focused on exploring this topic.

Objectives: To evaluate the comparative 2-year retention rate and the 12-month efficacy of adalimumab (ADA) as second biologic agent in etanercept (ETN) non-responder RA and PsA patients in a multicentre retrospective study.

Methods: All RA and PsA patients from 11 Italian Rheumatology Units treated with ADA after a first-course ETN failure and with at least 12-month follow-up were retrospectively collected in a multicentre registry. Data analysis was limited to the period from January 2002 to May 2016. Two-year ADA retention rate was calculated by Kaplan-Meier method. 12-month ADA response was defined as achievement of disease activity score 28 calculated by using erythrosedimentation (DAS28-ESR) $<2.6$ (remission) or $>2.6$ and $<3.2$ (low disease activity, LDA). Sub-analyses according to reason for ETN discontinuation and concomitant methotrexate in RA and PsA patients have been performed.

Results: The study population (219 patients) included 117 RA (female $85.5 \%$, mean $[ \pm$ standard deviation, SD] age $53.2 \pm 13.5$ years, mean $[ \pm S D]$ disease duration 10.1 \pm 7.7 ; positive rheumatoid factor $70.2 \%$; positive anti-citrullinated peptide antibodies $[\mathrm{ACPA}] 59.6 \%$; mean $[ \pm S D]$ baseline DAS28-ESR $4.97 \pm 1.3$; MTX users $64.9 \%$ ) and 102 PsA (female $63.7 \%$; mean [ \pm SD] age $51.7 \pm 10.6$; mean $[ \pm S D]$ disease duration $7.1 \pm 5.1$; mean $[ \pm S D]$ baseline DAS28-ESR 4.4 \pm 1.1 ; MTX users 50\%). The 2-year retention rate was $48.2 \%$ in RA and $56.5 \%$ in PsA patients, irrespective of reason for ETN discontinuation. Similarly, concomitant MTX was not associated with an increased drug survival in both RA $(p=0.09)$ and PsA ( $p=0.969)$ subgroup. 12-month clinical remission and LDA were achieved respectively in $27.3 \%$ and $23.9 \%$ RA patients, and $27.4 \%$ and $23.5 \%$ PsA patients. Conclusions: In our large real-life cohort, the use of ADA in primary and secondary ETN failures was highly effective in both RA and PSA patients, with more than $50 \%$ of ADA treated patients achieving remission or LDA. Reasons for ETN discontinuation were not associated with different ADA clinical response, as well as concomitant MTX.

Disclosure of Interest: None declared

DOI: 10.1136/annrheumdis-2017-eular.3747

\section{SAT0159 IMPACT OF PARTICIPATION IN THE ADALIMUMAB PATIENT SUPPORT PROGRAM ON FUNCTIONAL AND CLINICAL OUTCOMES AMONG PATIENTS WITH RHEUMATOID ARTHRITIS: PASSION STUDY}

F. Van den Bosch ${ }^{1}$, A. Ostor ${ }^{2}$, S. Wassenberg ${ }^{3}$, J.K. Anderson ${ }^{4}$, N. Chen ${ }^{4}$, C. Wang ${ }^{4}$, V. Garg ${ }^{4}$, J. Kalabic ${ }^{5} .{ }^{1}$ Ghent University Hospital, Ghent, Belgium ${ }^{2}$ Addenbrooke's Hospital, Cambridge, United Kingdom; ${ }^{3}$ Rheumazentrum, Ratingen, Germany; ${ }^{4}$ AbbVie Inc., North Chicago, United States; ${ }^{5}$ AbbVie Deutschland GmbH \& Co. KG, Ludwigshafen, Germany

Background: Patients (pt) with Rheumatoid arthritis (RA) who are treated with adalimumab (ADA) are offered a Patient Support Program (PSP) with variety of services. To date, no prospective study has been conducted to analyze the acceptance and the impact of these PSPs on treatment effectiveness and pt satisfaction

Objectives: The purpose of this study was to examine the effectiveness of ADA on rheumatoid arthritis (RA) treatment course in the context of PSP participation. Methods: PASSION (NCT01383421) was a 78-week (wk) post-marketing observational study of pts with RA receiving ADA in routine clinical care. Pts from the EU, Israel, Mexico, Puerto Rico, and Australia with an insufficient response to $\geq 1$ disease-modifying antirheumatic drug (DMARD) newly initiating ADA (1 prior 
biologic DMARD was allowed) were enrolled. The primary endpoint was the $\%$ of pts achieving the minimal clinically important difference (MCID; improvement of $\geq 0.22$ compared to baseline [BL]) in the Health Assessment Questionnaire Disability Index (HAQ-DI) at wk 78. Non-responder imputation (NRI) was used to account for the missing values. Secondary clinical parameters included $\%$ of pts achieving MCID in HAQ-DI at wks 24 and 52 and changes in the 28-joint DAS based on CRP (DAS28(CRP)), Simplified Disease Activity Index (SDAI), and Clinical Disease Activity Index (CDAl) at wks 24, 52, and 78 vs BL. Pts were categorized based on their participation in the PSP: ever (PSP users) vs never (PSP non-users) and outcomes were compared after adjusting for corresponding $B L$ values.

Results: Overall, the primary endpoint, percentage of pts achieving the MCID for HAQ-DI, was achieved by $72.1 \%$ (as observed) and $42.8 \%$ (NRI) of pts at week 78 with the percentage of pts achieving the MCID for HAQ-DI significantly higher in PSP users vs PSP non-users (48.1\% vs $37.8 \%$ [NRI]; $P<0.001)$. From 1,025 pts, $48.7 \%$ pts were PSP users (BL: mean age, 54.3 years (y); \% female, $77.1 \%$; mean RA duration, 7.8 y; mean HAQ-DI, 1.5; mean DAS28(CRP), 5.3; mean SDAI, 35.6; mean CDAI, 33.3; $17.8 \%$ pts had received prior biologic DMARD. Significant changes $(P \leq 0.05)$ from $\mathrm{BL}$ to wk 78 were observed for pts using the PSP vs PSP non-users in HAQ-DI (0.53 vs 0.39$)$, DAS28(CRP) ( -2.33 vs $-1.97)$, SDAl ( -24.5 vs -19.8$)$, and CDAl ( -22.66 vs -18.55$)$ scores (Figure). Study discontinuation rates were significantly $(P<0.001)$ lower among PSP-users vs PSP non- users ( $25.5 \%$ vs $41.6 \%)$. Reasons for discontinuations are listed in the Table.

Figure: Changes from baseline in DAS28 (CRP) (A), SDAI (B), CDAI (C), and HAQ-DI (D) over time between PSP users and PSP non-users.
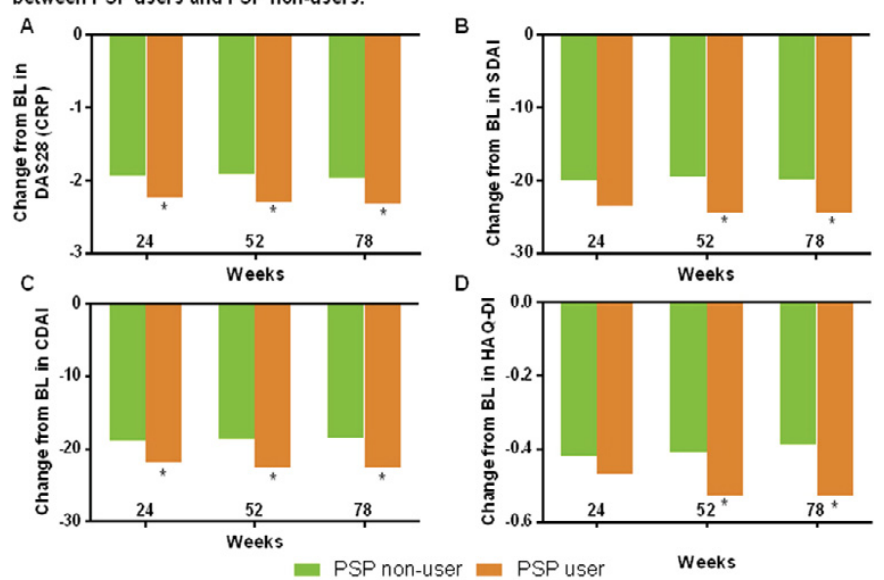

'sigrificartly ditterent between $P S P$ users and PSP non-1sers $P<0.05$ ) Data represented by LOCF imputdion for intertito treast pcopulation.

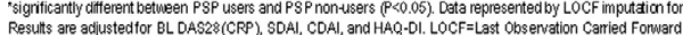

Table: All reasons for study discontinuation by PSP utilization category

\begin{tabular}{|l|c|c|c|}
\hline Subject Dispos ition & $\begin{array}{c}\text { All Patients } \\
\mathrm{N}=1025\end{array}$ & $\begin{array}{c}\text { PSP user } \\
\mathrm{N}=499\end{array}$ & $\begin{array}{c}\text { PSP non-user } \\
\mathrm{N}=526\end{array}$ \\
\hline Discontinued (\%) & $\mathbf{3 4 6}(33.8)$ & $\mathbf{1 2 7}(25.5)$ & $\mathbf{2 1 9 ( 4 1 . 9 )}$ \\
\hline Adverse event & $52(5.1)$ & $22(4.4)$ & $30(5.7)$ \\
\hline Withdrew consent & $37(3.6)$ & $13(2.6)$ & $24(4.6)$ \\
\hline Lost to follow-up & $46(4.5)$ & $17(3.4)$ & $29(5.5)$ \\
\hline Serious adverse events & $24(2.3)$ & $10(2.0)$ & $14(2.7)$ \\
\hline Lack of efficacy & $168(16.4)$ & $66(13.2)$ & $102(19.4)$ \\
\hline Other & $51(5.0)$ & $16(3.2)$ & $35(6.7)$ \\
\hline
\end{tabular}

Conclusions: The final study results showed that, in pts with moderate to severe RA who initiated ADA, significantly better improvement in functional and clinical outcomes was achieved in the PSP users vs the PSP non-users. Improvements were achieved at early timepoints and continued to increase throughout the study. Acknowledgements: AbbVie funded the study and the analysis, and approved the abstract for submission. Medical writing assistance was provided by Gaurav Patki, PhD and Benjamin Wolfe, PhD from AbbVie.

Disclosure of Interest: F. Van den Bosch Consultant for: AbbVie, Celgene, Janssen, Pfizer, and UCB, Speakers bureau: AbbVie, Celgene, Janssen, Pfizer, and UCB, A. Ostor Consultant for: Roche, Chugai, MSD, AbbVie, Pfizer, Novartis, Napp, and BMS, S. Wassenberg Consultant for: AbbVie, Celgene, Novartis, Pfizer, MSD, Lilly, Janssen and UCB, Speakers bureau: AbbVie, Celgene, Novartis, Pfizer, MSD, Lilly, Janssen and UCB, J. K. Anderson Shareholder of: AbbVie, Employee of: AbbVie, N. Chen Shareholder of: AbbVie, Employee of: AbbVie, C. Wang Shareholder of: AbbVie, Employee of: AbbVie, V. Garg Shareholder of: AbbVie, Employee of: AbbVie, J. Kalabic Shareholder of: AbbVie, Employee of: AbbVie DOI: 10.1136/annrheumdis-2017-eular.1876

\section{SAT0160 IMMUNOGENICITY OF BIOSIMILARS FOR THE TREATMENT OF INFLAMMATORY RHEUMATIC DISEASES: A REVIEW FROM CONFIRMATORY CLINICAL TRIALS}

F. Araújo $^{1,2}$, J. Gonçalves ${ }^{3}$, J.E. Fonseca ${ }^{4,5},{ }^{1}$ Rheumatology, Hospital de Sant'Ana, SCML, Cascais; ${ }^{2}$ Institute of Microbiology, Faculdade de Medicina da Universidade de Lisboa, Lisboa; ${ }^{3}$ Med-Research Institute of Medicines, Faculdade de Farmácia da Universidade de Lisboa; ${ }^{4}$ Rheumatology, Hospital de Santa Maria, Lisbon Academic Medical Centre, Lisbon; ${ }^{5}$ Rheumatology Research Unit, Instituto de Medicina Molecular, Faculdade de Medicina, Universidade de Lisboa, Lisboa, Portugal

Background: The assessment of immunogenicity is mandatory during the comparability exercise of biosimilar candidate drugs, as even small structural differences can potentially elicit antidrug antibodies (ADA) and affect efficacy and safety.

Objectives: To review the incidence of ADA and neutralizing ADA (nADA) in confirmatory clinical trials of biosimilar drugs approved for the treatment of inflammatory rheumatic conditions in the European and North-American markets; to review the type of assays used for this purpose; to compare the incidence of ADA with historical data from reference biotechnological drugs.

Methods: We performed a literature search in the Medline database and hand searched EULAR and ACR meeting abstracts to identify phase I and III confirmatory clinical trials of biosimilar drugs for the treatment of rheumatic conditions approved in the European and North-American markets. Open-label extensions involving biological switch were not included. All outcomes regarding immunogenicity were extracted (ADA, nADA and type of immunogenicity assays). Results: We screened 255 articles by title and abstract and 7 publications fulfilled our inclusion criteria. Three meeting abstracts were also included. Six studies assessed infliximab biosimilars (CT-P13 and SB2), three studies assessed etanercept biosimilars (SB4 and GP2015) and one study assessed an adalimumab biosimilar (ABP 501). All but two concerned phase III trials and seven were performed on rheumatoid arthritis patients. All biosimilars had comparable immunogenicity profiles in respect to their reference drugs, except for the etanercept biosimilar SB4, which presented significantly less ADA when compared to reference etanercept $(0.7 \%$ vs $13.1 \%$ at 24 weeks and $1.0 \%$ vs $13.2 \%$ at 52 weeks, $p<0.001$ for both). As expected, infliximab had the highest incidence of ADA; the proportion of ADA in studies of infliximab and adalimumab was higher when compared to historical data. Only 4 studies reported nADA, which were highest in the infliximab biosimilar CT-P13 54-week study in ankylosing spondylitis patients. Electrochemiluminescence immunoassay was the preferred method to measure ADA. Table 1 summarizes the main findings in the included studies.

Table 1. Immunogenicity of biosimilars approved for the treatment of inflammatory rheumatic diseases. ADA: antidrug antibody, NA: not available, nADA: neutralizing antidrug antibody. ${ }^{*} T$ The EGALITY study presented a four-arm design in which two arms were continuously treated with either reference etanercept or GP2015 and the other two arms were systematically switched. The results presented in this table concern the groups continuously treated with reference etanercept or GP2015

\begin{tabular}{|c|c|c|c|c|c|c|}
\hline $\begin{array}{l}\text { Study } \\
\text { population }\end{array}$ & & \begin{tabular}{|l|} 
Reference \\
drug ADA (x)
\end{tabular} & $\begin{array}{l}\text { Reference } \\
\text { drug nADA (x) }\end{array}$ & $\begin{array}{l}\text { Biosimilar } \\
\text { ADA }\end{array}$ & $\begin{array}{l}\text { Biosimilar } \\
\text { nADA (\$) }\end{array}$ & ADA/RADA assoy \\
\hline \multirow{11}{*}{$\begin{array}{l}\text { Rheumatoid } \\
\text { srthritis }\end{array}$} & \multicolumn{6}{|c|}{ C.P13 (Infliximab) } \\
\hline & $\begin{array}{l}\text { YOO } 2013 \\
\text { (PLANETRA, } 30 \mathrm{w} \text { ) }\end{array}$ & 48.2 & NA & 48.4 & NA & $\begin{array}{l}\text { Electrochemiluminescence } \\
\text { immunosssy/NA }\end{array}$ \\
\hline & $\begin{array}{l}\text { Yoo } 2016 \\
\text { (PLANETRA, 54 w) }\end{array}$ & 36.0 & NA & 41.1 & NA & $\begin{array}{l}\text { Electrochemiluminescence } \\
\text { immunoassay/ flow-through } \\
\text { immunoassay }\end{array}$ \\
\hline & \multicolumn{6}{|l|}{ S82 (infliximab) } \\
\hline & Choe 2015 (30 w) & 49.7 & NA & 55.1 & $\mathrm{NA}$ & $\begin{array}{l}\text { Electrochemiluminescence } \\
\text { immunoassay/ competitive ligand- } \\
\text { binding assay }\end{array}$ \\
\hline & Choe $2015(54 \mathrm{w})$ & 57.5 & NA & 62.4 & NA & NA \\
\hline & \multicolumn{6}{|l|}{ SBA (etanercept) } \\
\hline & Emery $2015(24 \mathrm{w})$ & 13.1 & 3 & 0.7 & 0 & $\begin{array}{l}\text { Electrochemiluminescence } \\
\text { immunoassay/ competitive ligand- } \\
\text { binding assoy }\end{array}$ \\
\hline & $\begin{array}{l}\text { Vencovsky } 2015 \\
(52 \mathrm{w})\end{array}$ & 13.2 & NA & 1.0 & NA & NA \\
\hline & \multicolumn{6}{|c|}{ ABP 501 (adalimumab) } \\
\hline & Cohen $2015(24 \mathrm{w})$ & 38.2 & 11.1 & 38.3 & 9.1 & NA \\
\hline \multirow{3}{*}{$\begin{array}{l}\text { Ankylosing } \\
\text { spondyilitis }\end{array}$} & \multicolumn{6}{|c|}{ cr.P13 (infliximab) } \\
\hline & $\begin{array}{l}\text { Park } 2013 \\
\text { (PLANETAS, } 30 \mathrm{w} \text { ) }\end{array}$ & 22.5 & NA & 27.4 & NA & $\begin{array}{l}\text { Electrochemiluminescence } \\
\text { immunoassay/NA }\end{array}$ \\
\hline & $\begin{array}{l}\text { Park 2016 } \\
\text { (PLANETAS, } 54 \text { w) }\end{array}$ & 23.0 & 100 & 19.5 & 100 & $\begin{array}{l}\text { Electrochemiluminescence } \\
\text { immunoassay/ flow-through } \\
\text { immunoassay }\end{array}$ \\
\hline \multirow[t]{2}{*}{ Psoriasis } & \multicolumn{6}{|c|}{ GP2015 (etanercept) } \\
\hline & $\begin{array}{l}\text { Griffiths } 2016 \\
\text { (EGALTY, 52 w)* }\end{array}$ & 2.9 & 0 & 0 & 0 & $\begin{array}{l}\text { Electrochemiluminescence } \\
\text { immunoassay/ competitive ligand. } \\
\text { binding assay }\end{array}$ \\
\hline
\end{tabular}

Conclusions: Currently approved biosimilars for the treatment of rheumatic diseases have comparable immunogenicity profiles in respect to their reference drugs. The discrepancy in ADA between SB4 and reference etanercept did not correlate with efficacy or safety and did not preclude biosimilarity, according to the regulatory agencies. The higher proportion of ADA compared to historical data may be explained by the greater sensitivity of current immunogenicity assays, such as electrochemiluminescence.

Disclosure of Interest: None declared

DOI: 10.1136/annrheumdis-2017-eular.2486 